Review / Meta-analyses

\title{
Emotion dysregulation and non-suicidal self-injury: A systematic review and meta-analysis
}

\author{
Jennifer C. Wolff*, Elizabeth Thompson, Sarah A. Thomas, Jacqueline Nesi, \\ Alexandra H. Bettis, Briana Ransford, Katie Scopelliti, Elisabeth A. Frazier, Richard T. Liu
}

The Alpert Medical School of Brown University, 1 Hoppin St, Suite 204, 02093, Providence, RI, United States

\section{A R T I C L E I N F O}

\section{Article history:}

Received 4 December 2018

Received in revised form 15 March 2019

Accepted 17 March 2019

Available online 12 April 2019

\section{Keywords:}

Suicide

Miscellaneous

\begin{abstract}
A B S T R A C T
Background: Over the past several years there has been considerable interest in the relation between emotion dysregulation and non-suicidal self-injury (NSSI), particularly given that rates of NSSI have been increasing and NSSI is a critical risk factor for suicidal behavior. To date, however, no synthesis of empirical findings exists.

Methods: The present study presents a comprehensive meta-analytic review of the literature on the association between NSSI and emotion dysregulation. A total of 48 publications, including 49 independent samples, were included in this analysis.

Results: Overall, a significant association was found between emotion dysregulation and NSSI (pooled $\mathrm{OR}=3.03[95 \% \mathrm{CI}=2.56-3.59])$. This association was reduced but remained significant $(\mathrm{OR}=2.40[95 \%$ $\mathrm{CI}=2.01-2.86]$ ) after adjustment for publication bias. Emotion dysregulation subscales most strongly associated with NSSI included limited access to regulation strategies, non-acceptance of emotional responses, impulse control difficulties, and difficulties engaging goal-directed behavior. Lack of emotional awareness/clarity and cognitive aspects of dysregulation yielded weaker, yet significant, positive associations with NSSI.

Conclusions: Findings support the notion that greater emotion dysregulation is associated with higher risk for NSSI among individuals across settings, regardless of age or sex. Furthermore, findings reveal facets of dysregulation that may have unique implications for NSSI. This meta-analysis highlights the importance of better understanding emotion dysregulation as a treatment target for preventing NSSI.
\end{abstract}

(C) 2019 Elsevier Masson SAS. All rights reserved.

\section{Introduction}

Non-suicidal self-injury (NSSI), defined as the deliberate destruction of bodily tissue without suicidal intent [1], is increasingly recognized as a significant public health concern: lifetime prevalence rates of NSSI have been estimated between $5.5 \%$ in adults to $17.2 \%$ in adolescents [2]. Among clinical inpatient samples, as many as $21 \%$ of adults [3] and 30-45\% of adolescents [4,5] engage in NSSI, with rates of this behavior increasing over the past several decades [6]. Importantly, clear associations have been identified between NSSI and suicidal behavior [7], and in some cases NSSI is an even stronger predictor of suicide attempts than past suicidal behavior [8-10]. Thus, it is critical to understand factors that may predispose individuals to engage in NSSI in order to inform treatment and prevention efforts.

One construct that has featured prominently in prior research on NSSI is emotion regulation, broadly defined as implicit or

\footnotetext{
* Corresponding author.

E-mail address: jennifer_wolff@brown.edu (J.C. Wolff).
}

explicit efforts to recognize, understand, and manage one's emotions [11-14]. Theoretical and empirical work has identified self-injurious behavior, including NSSI, as both a consequence of poor emotion regulation [15] and a maladaptive strategy for regulating affect [1]. However, despite the size and scope of this literature, no synthesis of empirical findings currently exists. Furthermore, the construct of emotion (dys)regulation lacks conceptual clarity $[16,14]$. This is illustrated by the wide range of self-report measures used to assess emotion regulation, each capturing different aspects of this broad construct [17,18]. As research examining NSSI begins to incorporate a growing array of novel measures and methodologies, it is necessary to synthesize prior research on the multidimensional nature of emotion regulation, as documented by self-report measures.

\subsection{Overview of emotion dysregulation: models and measures}

There have been many theoretical models proposed that characterize emotion regulation. Importantly, the regulation of emotions involves many neurobiological and physiological 
processes, such as emotion recognition, emotion reactivity, and cognitive control [19-21]. For the purposes of the current review, we focus on abilities and strategies that are reflective of emotion dysregulation. Below we discuss theoretical models of emotion regulation commonly used in the literature and their associated measures.

According to the process model of emotion regulation [22], emotions are generated and expressed over a multi-stage process, with various regulation strategies available at each stage. This model specifies that regulation must involve awareness of one's emotion, goals to regulate those emotions, (e.g., by increasing or decreasing their intensity), and the effective implementation of adaptive strategies to reach emotion-regulation goal [23]. Strategies are differentiated by whether they occur before (antecedentfocused) or after (response-focused) an emotional response, and may be implicit, i.e., automatic, or explicit, i.e., effortful [24]. In the extended process model of emotion regulation, Gross and colleagues highlight three points at which difficulties in the regulation process may occur: identification, selection of a strategy, and implementation or modification of a strategy [19]. As such, emotion dysregulation may be due to a failure to engage in any regulation, difficulties enacting a strategy successfully, or by using regulation strategies that are poorly matched to a situation. To date, the measurement of this construct has largely focused on self-report methods that assess strategy selection - what strategies do individuals rely on to regulate emotional responses.

Drawing on this framework, the Emotion Regulation Questionnaire (ERQ) [25] captures two specific strategies of emotion regulation: reappraisal, an antecedent-focused cognitive change strategy aimed to change the way one thinks about a situation, and expressive suppression, a response-focused strategy aimed to inhibit emotional expression, with the former generally deemed more effective than the latter [24]. Another frequently used measure, the Cognitive Emotion Regulation Questionnaire (CERQ) [26] also emphasizes conscious, cognitive regulation strategies. A number of adaptive strategies are identified for managing the intake of emotional information, including cognitive strategies such as positive reappraisal and acceptance, and maladaptive strategies include rumination, self-blame, blaming others, and catastrophizing [27].

In contrast to the measures noted above, other models have emphasized the need for awareness or understanding of one's emotions and modulation of emotional reactivity and intensity $[11,13]$. Mapping onto the process model of emotion regulation, this framework emphasizes the identification of one's own emotional reactions as a critical step in successful regulation, as well as the selection of appropriate strategies to regulate these responses. This broad, multidimensional conceptualization of emotion regulation resulted in the development of the Difficulties in Emotion Regulation Scale (DERS) [11]. The DERS, one of the most widely used measures of emotion regulation, draws on six theoretical facets of regulation: awareness of one's emotions; understanding of how one is feeling (clarity); flexible modulation of emotions in order to engage in goal-directed behaviors; control over impulsive behaviors in the face of negative emotion; acceptance of emotional responses; and access to emotion regulation strategies. The absence of any of these abilities signifies emotion dysregulation [11].

As noted above, the constructs of emotion regulation and dysregulation are broad and multidimensional. The literature has largely examined the extent to which broad domains and/or specific strategies are adaptive or maladaptive. Thus, the current review aims to synthesize this literature by examining both overall dysregulation and deficits within specific domains of emotion regulation with regard to NSSI. As there has been no single, unitfying conceptual model for emotion (dys)regulation in the literature to date, the current meta-analysis examines subscales from each of these three measures in the analyses below.

\subsection{Emotion dysregulation and NSSI}

As emotion dysregulation becomes central to our understanding of psychopathology more broadly [16,17], it has achieved greater recognition as a potential risk factor for engagement in NSSI. Various models of NSSI characterize the behavior as a maladaptive response to strong negative affect, with theoretical and empirical work suggesting that NSSI may serve an affective regulation function [28-31], stemming from poor emotion regulation skills (i.e., emotion dysregulation). For example, the argument that NSSI serves the function of avoidance or escape from unwanted emotional arousal is set forth in the experiential avoidance model of deliberate self-harm [30]. This need for avoidance is exacerbated by individuals' emotion regulation skill deficits, poor distress tolerance, and difficulty modulating negative emotions when aroused. Similarly, a direct link is proposed between emotion dysregulation and dysregulated behaviors (such as NSSI) among individuals with borderline personality disorder in the emotional cascade model [32]. This model suggests that rumination intensifies emotional experiences, leading individuals to engage in dysregulated behaviors as a temporary distraction from negative emotion. Most contemporary models of NSSI now recognize the potential contribution of emotion regulation deficits, as well as individual factors that may exacerbate those deficits (e.g., high levels of aversive emotions and cognitions, acute negative affective states [1,30].

Despite widespread recognition that emotion dysregulation may contribute risk for NSSI, no systematic review of empirical studies has been conducted. A recent meta-analysis of longitudinal risk factors for NSSI found affect dysregulation to be a significant, but weak, predictor of NSSI [33]. In this metaanalysis, however, affect dysregulation was broadly defined to include emotional suppression, emotional reactivity, and negative affect. In addition to the need to distinguish the role of emotion regulation as separate from emotional reactivity and other aspects of affective experiences, questions remain regarding which, if any, specific dimensions of emotion dysregulation may contribute higher levels of risk. Several studies offer preliminary insights into the importance of considering discrete facets of emotion regulation in understanding risk for NSSI. For example, a recent study of psychiatrically hospitalized adolescents found higher risk for chronic suicidal behavior among those reporting non-acceptance of emotional responses and limited access to emotion regulation strategies, compared to other domains of emotion dysregulation on the DERS [34]. A study specifically examining NSSI reached similar conclusions, with limited access to emotion regulation strategies showing unique associations with self-injurious behavior [15]. A synthesis of the empirical literature is warranted to better characterize differential associations between these dimensions of emotion dysregulation and NSSI, as well as to examine potential moderators of these associations. Such findings have the potential to offer valuable, clinically relevant information highlighting aspects of emotion dysregulation that should be targeted in interventions.

We present a systematic meta-analysis to characterize overall associations between self-reported measures of emotion dysregulation and NSSI. In order to clarify the role of the various dimensions of emotion dysregulation, we also examined associations between NSSI and specific dimensions of emotion dysregulation. Finally, based on our comprehensive review, we discuss important gaps in the literature with the view of informing future research in this area. 


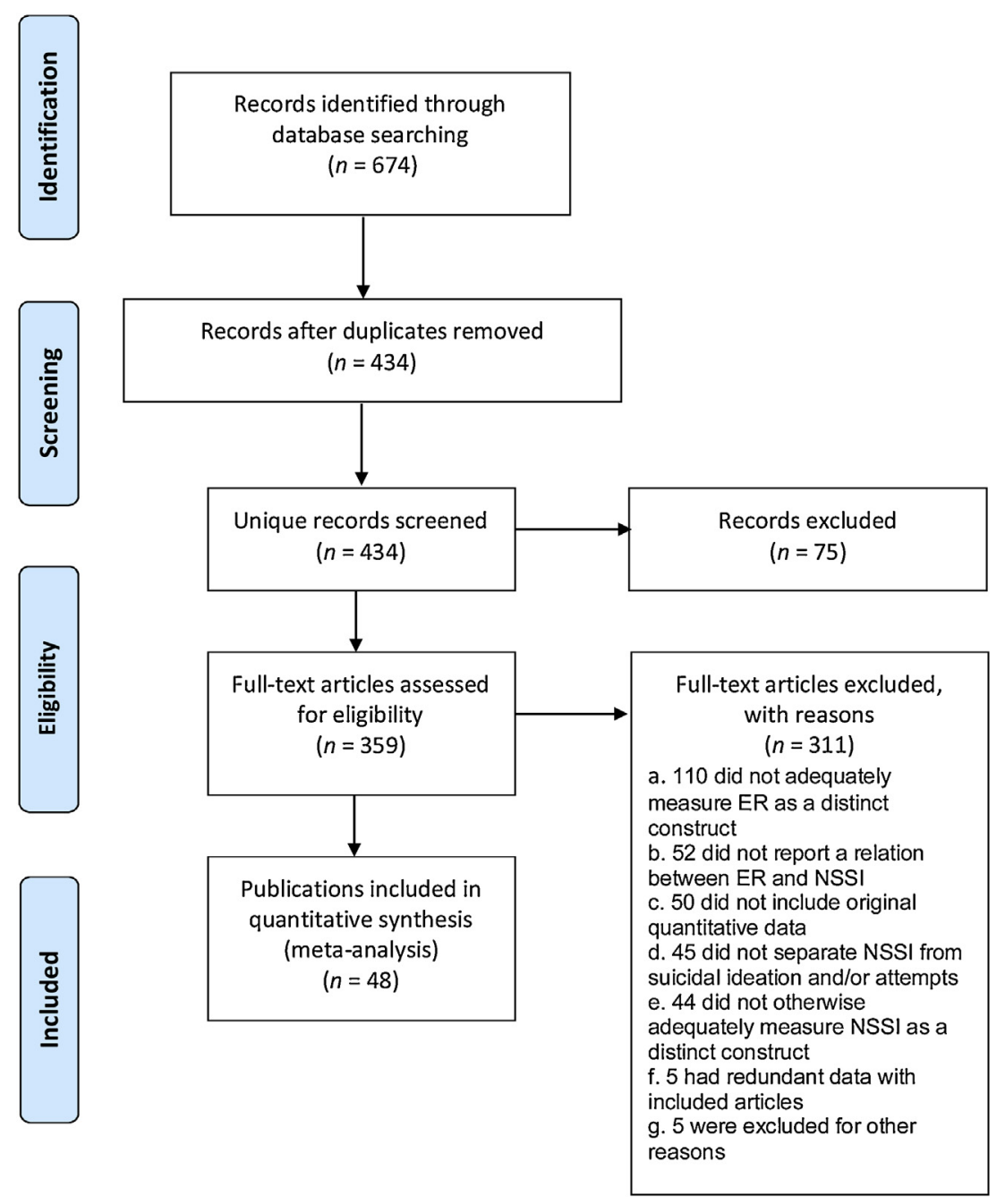

Fig. 1. PRISMA flow chart of literature search.

\section{Methods}

\subsection{Search strategy and eligibility criteria}

To identify relevant studies for inclusion in this review, we conducted a systematic search of the literature in PsycINFO and Medline using the following search string: ("emotion modulation" or "affect modulation" or "affective modulation" or "emotion reactivity" or "emotional reactivity" or "affect reactivity" or "affective reactivity" or "emotion regulation" or "emotion dysregulation" or "affect regulation" or "affect dysregulation" or "affective regulation" or "affective dysregulation" or "affective functioning" or "emotional functioning" or "distress tolerance" or "affective labelling" or "affective labeling" or "affect labelling" or "affect labeling" or "emotion labelling" or "emotion labeling") ${ }^{1}$ AND (self-injur* or mutilat* or self-cut* or self-harm*). We retained only the search results from: (i) English-language publications and (ii) peer-reviewed journal publications. Using this search strategy generated 674 articles, of which 434 were unique reports. We determined eligibility by reviewing title and abstract; however, in cases where eligibility could not be

\footnotetext{
${ }^{1}$ Although the current review focused exclusively on emotion regulation, we included search terms for distinct but related constructs (e.g., affective reactivity and distress tolerance) so as to be as comprehensive in our search as possible).
}

determined based on title and abstract alone, we also reviewed the full text. Each search result was reviewed by two independent raters for eligibility, with discrepancies resolved by a third rater.

The study inclusion criteria were: (i) any form of emotion (dys) regulation was assessed, distinct from other related constructs (therefore studies assessing related constructs, such as emotional reactivity or emotional processing were not included); (ii) consistent with the definition of NSSI, the measure of NSSI had to specify there was no suicidal intent; (iii) emotion dysregulation had to be measured as distinct from NSSI (e.g., not as a function of NSSI); and (iv) quantitative data were presented on the association between any form of emotion dysregulation and any NSSI. To provide clarity on some data, authors of studies were contacted as necessary.

We excluded 75 reports based on their titles and abstracts because they did not meet the inclusion criteria reviewed above. After this initial screen, we excluded an additional 311 articles as a result of a detailed full-text review. There were 48 publications remaining that satisfied the eligibility criteria (see Fig. 1 for PRISMA flow chart). We excluded studies after full-text review because they: (i) did not adequately measure emotion dysregulation as a distinct construct $(\mathrm{n}=110)$; (ii) did not report any measures of association between emotion dysregulation and NSSI $(\mathrm{n}=52)$; (iii) did not include original quantitative data $(\mathrm{n}=50)$; (iv) did not separate NSSI from suicidal ideation and/or attempts $(\mathrm{n}=45)$; ( $\mathrm{v})$ did not otherwise adequately measure NSSI as a 
Table 1

Study characteristics.

\begin{tabular}{|c|c|c|c|c|c|c|c|}
\hline Study Author(s) (year) & $\mathrm{N}^{\mathrm{a}}$ & $\begin{array}{l}\% \\
\text { Female }^{\mathrm{a}}\end{array}$ & $\begin{array}{l}\text { Mean } \\
\text { Age }^{a}\end{array}$ & Sample & $\begin{array}{l}\text { Emotion Regulation Measure } \\
(\mathrm{s})\end{array}$ & NSSI Measure(s) & NSSI time frame \\
\hline \multicolumn{8}{|l|}{ Non-Suicidal Self-Injury } \\
\hline [36] Anderson \& Crowther & 214 & 70.09 & 18.86 & Community & Self-report (DERS) & Self-report (DSHI) & Lifetime \\
\hline [37] Anestis et al. Study $1^{\mathrm{b}}$ & 1317 & 78.80 & 21.12 & Community & Self-report (DERS) & Self-report (DSHI) & Lifetime \\
\hline [37] Anestis et al. Study 3 & 93 & 45.20 & 36.25 & Clinical & Self-report (DERS) & Self-report (DSHI) & Lifetime \\
\hline [38] Arbuthnott et al. & 342 & 79.20 & 18.61 & Community & Self-report (DERS) & Self-report (DSHI) & Lifetime \\
\hline [39] Bjureberg et al. Study 1 & 96 & 100 & 25.37 & Clinical & Self-report (DERS) & Self-report (DSHI) & 4 months \\
\hline [39] Bjureberg et al. Study 2, Sample 1 & 99 & 63.64 & 24.68 & Community & Self-report (DERS) & Self-report (DSHI) & 4 months \\
\hline [39] Bjureberg et al. Study 2, Sample 2 & 465 & 100 & 21.75 & Community & Self-report (DERS) & Self-report (DSHI) & Lifetime \\
\hline $\begin{array}{l}\text { [40] Bracken-Minor \& McDevitt- } \\
\text { Murphy }\end{array}$ & 444 & 79.80 & 21.30 & Community & Self-report (DERS) & Self-report (ISAS) & Lifetime \\
\hline [41] Buckholdt et al. Study 1 & 118 & 76.00 & 20.90 & Community & Self-report (DERS) & Self-report (DSHI) & Lifetime \\
\hline [41] Buckholdt et al. Study 2 & 82 & 48.00 & 36.60 & Clinical & Self-report (DERS) & Self-report (DSHI) & Lifetime \\
\hline [42] Burke et al. & 177 & 72.00 & 18.69 & At-risk & Self-report (RPAS) & Self-report (FAFSI) & 12 months \\
\hline [43] Cerutti et al. & 294 & 62.74 & 23.34 & Community & Self-report (CERQ) & Self-report (DSHI) & Lifetime \\
\hline [44] Chaplo et al. ${ }^{c}$ & 525 & 25.33 & 16.11 & Community & Self-report (DERS) & Self-report (LSASIC) & Lifetime \\
\hline [45] Duggan et al. c,d & 120 & 56.67 & 12.34 & Community & Self-report (DERS) & Self-report (HIDS) & Lifetime \\
\hline [46] Emery et al. & 86 & 88.37 & 19.93 & Community & Self-report (DERS) & Self-report (HIDS) & Lifetime \\
\hline [47] Franklin et al. & 42 & 57.14 & 21.86 & Community & Self-report (DERS) & Interview (SITBI) & Lifetime \\
\hline [48] Gardner et al. & 179 & 0 & 37.70 & At-risk & Self-report (CERQ) & Self-report (ISAS) & Lifetime \\
\hline [49] Glenn \& Klonsky & 198 & 73.74 & 15.12 & Clinical & Self-report (DERS) & Self-report (ISAS) & Lifetime \\
\hline [50] Gomez-Exposito et al. & 85 & 100 & 28.31 & Clinical & Self-report (DERS) & Interview (SSM) & Lifetime \\
\hline [51] Gratz \& Chapman & 79 & 0 & 22.67 & Community & Self-report (DERS) & Self-report (DSHI) & Lifetime \\
\hline [52] Gratz \& Roemer & 249 & 100 & 23.29 & Community & Self-report (DERS) & Self-report (DSHI) & Lifetime \\
\hline [53] Gratz \& Tull & 61 & 46.00 & 44.45 & Clinical & Self-report (DERS) & Self-report (DSHI) & Lifetime \\
\hline $\begin{array}{l}\text { [54,55] Gratz et al.; Muehlenkamp } \\
\text { et al. }\end{array}$ & 398 & 76.40 & 20.25 & Community & Self-report (DERS) & Self-report (DSHI) & Lifetime \\
\hline [56] Hasking et al. & 211 & 77.73 & 21.29 & Community & Self-report (ERQ) & Interview (SSM) & Lifetime \\
\hline [57] Hasking et al. & 393 & 68.45 & 14.80 & Community & Self-report (ERQ) & Interview (SSM) & Lifetime \\
\hline [58] Heath et al. & 46 & 89.13 & 20.24 & Community & Self-report (DERS) & Self-report (HIDS) & Lifetime \\
\hline [59] Horgan \& Martin & 201 & 79.07 & 20.09 & Community & Self-report (ERQ) & Self-report (SIQ) & Lifetime \\
\hline [60] Kleiman et al. & 2485 & 62.20 & 20.79 & Community & Self-report (DERS) & Self-report (FAFSI) & Lifetime \\
\hline [61] Kranzler et al. & 148 & 70.90 & 21.48 & Community & Self-report (DERS) & $\begin{array}{l}\text { Self-report (DSHI) \& Interview (L- } \\
\text { SASI) }\end{array}$ & Lifetime \\
\hline [62] Lear \& Pepper & 146 & 83.56 & 19.31 & Community & Self-report (DERS) & Self-report (ISAS) & Lifetime \\
\hline [63] Levesque et al. & 797 & 81.90 & 19.65 & Community & Self-report (DERS) & Self-report (OSI) & 6 months \\
\hline [64] Martin et al. & 455 & 43.00 & 40.11 & Clinical & Self-report (DERS) & Self-report (DSHI) & 12 months \\
\hline [65] Muehlenkamp \& Brausch & 2064 & 71.70 & 21.05 & Community & Self-report (CERQ) & Interview (SITBI) & Lifetime \\
\hline [66] Muehlenkamp et al. & 1855 & 66.00 & 19.70 & Community & Self-report (DERS) & Self-report (DSHI) & Lifetime \\
\hline [67] Muehlenkamp et al. & 124 & 100 & 19.69 & Clinical & Interview (EDI-ER subscale) & Self-report (DSHI) & Lifetime \\
\hline [68] Navarro-Haro et al. & 65 & 100 & 27.48 & Clinical & Self-report (ERQ) & Self-report (BPD- CDI) & 6 months \\
\hline$[15,69]$ Perez et al.; Sharp et al. ${ }^{\mathrm{f}}$ & 218 & 58.70 & 15.93 & Clinical & Self-report (DERS) & Self-report (DSHI) & Lifetime \\
\hline [70] Peters et al. & 411 & 67.90 & 19.19 & Community & Self-report (DERS) & Self-report (PAI-BOR) & Lifetime \\
\hline [71] Preyde et al. & 100 & 74.38 & 15.74 & Clinical & Self-report (DERS) & Self-report (OSI) & 1 month \\
\hline [72] Selby et al. & 142 & 76.80 & 18.75 & Community & Self-report (CERQ) & Self-report (FASM) & 12 months \\
\hline [73] Somma et al. & 122 & 76.20 & 16.69 & Community & Self-report (DERS) & Self-report (DSHI) & Lifetime \\
\hline$[74,75]$ Tatnell et al.; Voon et al. ${ }^{\mathrm{d}, \mathrm{f}}$ & 2637 & 67.99 & 13.90 & Community & Self-report (ERQ) & Self-report (SHBQ) & Lifetime \\
\hline [76] Turner et al. ${ }^{\mathrm{e}}$ & 211 & 93.40 & 22.94 & At-risk & Self-report (DERS) & Self-report (QNSSI) & 3 months \\
\hline [77] Vieira et al. & 61 & 92.40 & 25.38 & Clinical & Self-report (DERS) & Self-report (SIQ-TR) & Lifetime \\
\hline [78] Weinberg \& Klonsky & 72 & 63.89 & 20.24 & Community & Self-report (DERS) & Self-report (ISAS) & Lifetime \\
\hline [79] Wilcox et al. ${ }^{\mathrm{e}}$ & 1081 & 54.00 & NR & Community & Self-report (DI) & Interview (SSM) & 12 months \\
\hline [80] Williams \& Hasking & 289 & 73.01 & 22.52 & Community & Self-report (ERQ) & Interview (SSM) & Lifetime \\
\hline [81] Yurkowski et al. & 1153 & 79.00 & 19.35 & Community & Self-report (DERS) & Self-report (OSI) & 6 months \\
\hline [82] Zelkowitz et al. & 355 & 79.10 & 18.62 & Community & DERS, ERQ, REQ & Self-report (ISAS) & Lifetime \\
\hline
\end{tabular}

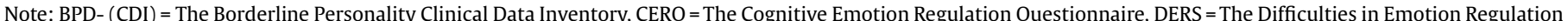

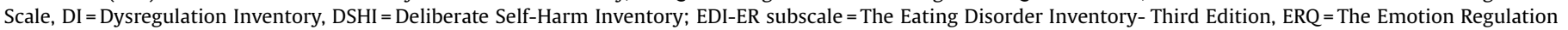

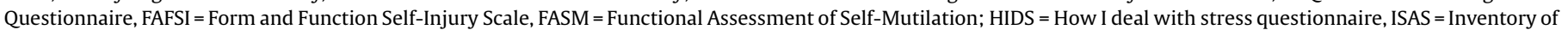

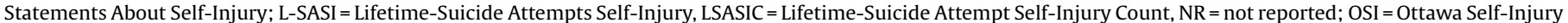

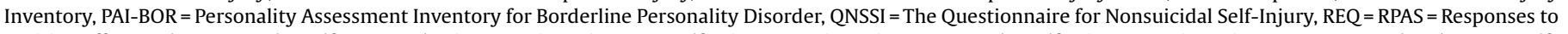

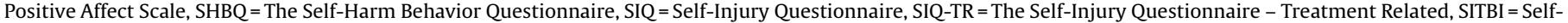
Injurious Thoughts and Behaviors Interview; SSM = study-specific measure.

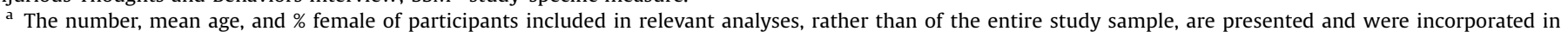
moderator analyses whenever available.

$\mathrm{b}$ This publication included another sample that was not eligible for the current meta-analysis.

c Separate effects were reported by sex.

d These studies employed a longitudinal design but cross-sectional analyses of emotion regulation in relation to NSSI.

e These studies employed longitudinal analyses of emotion regulation in relation to NSSI.

${ }^{\mathrm{f}}$ In these cases, two publications drew on overlapping samples but were retained because each publication featured unique data relevant to the current meta-analysis (e.g.,

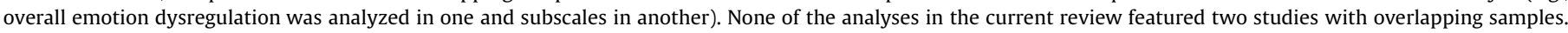
Table 2. Meta-analytic results for the Difficulties in Emotion Regulation Scale in relation to non-suicidal self-injury. 
distinct construct $(\mathrm{n}=44)$; and (vi) had redundant data with included articles $(n=5)$; (vii) excluded for other reasons $(n=5)$. In cases where it could not be independently determined whether two studies contained overlapping samples, the study authors

(a)

Funnel Plot of Standard Error by Log odds ratio

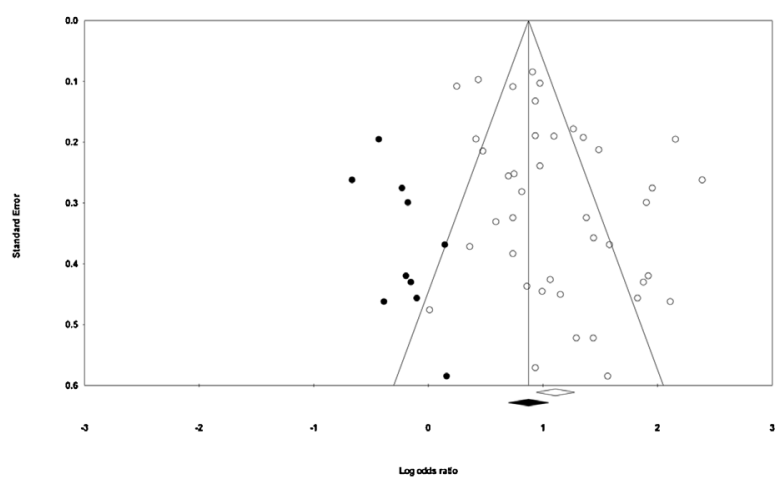

(c)

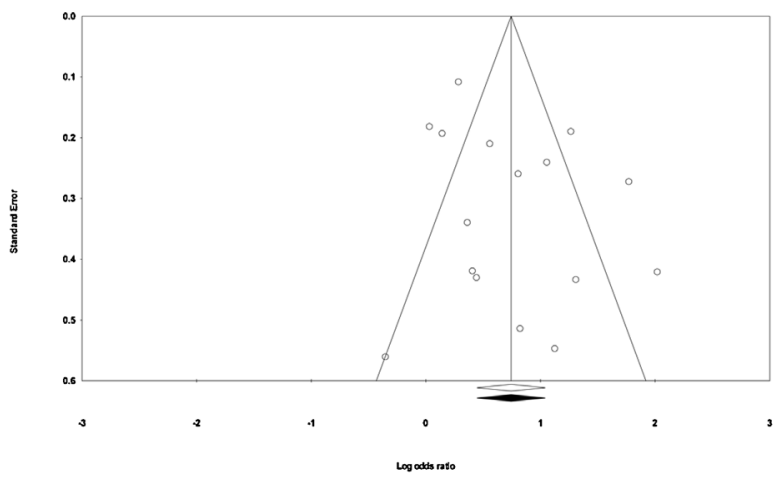

(e)

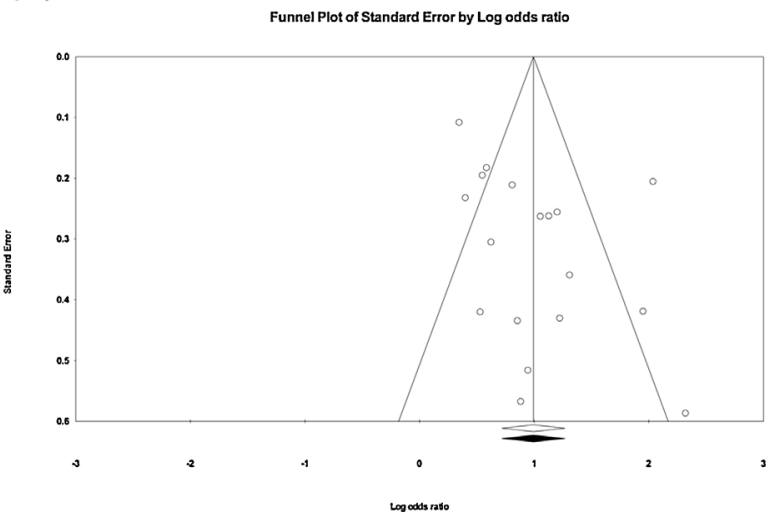

were contacted. In five cases where studies were excluded for having samples that overlapped with those in retained studies, the study that provided the larger sample was retained in every case.

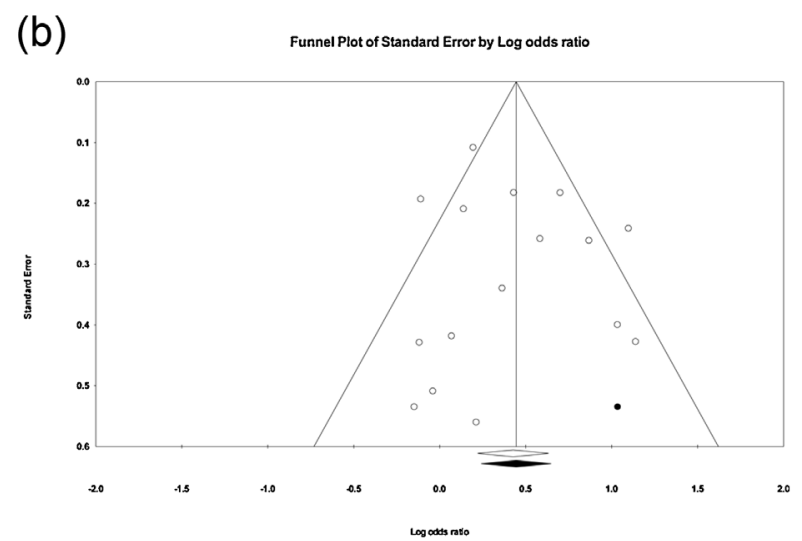

(d)

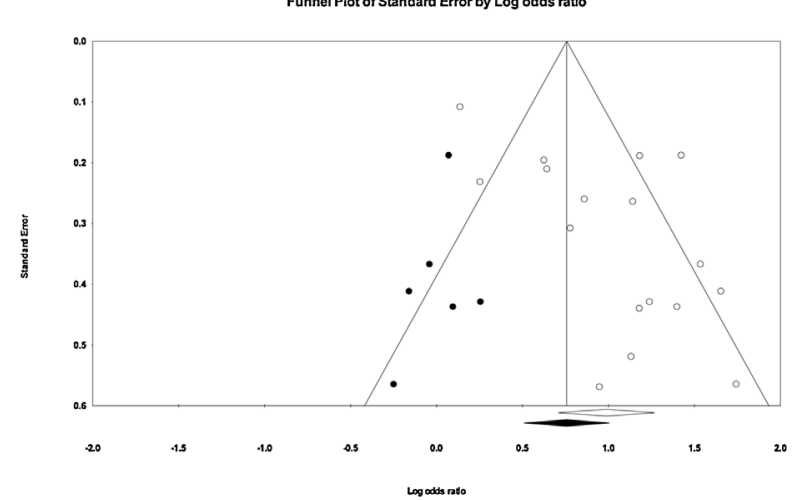

(f)

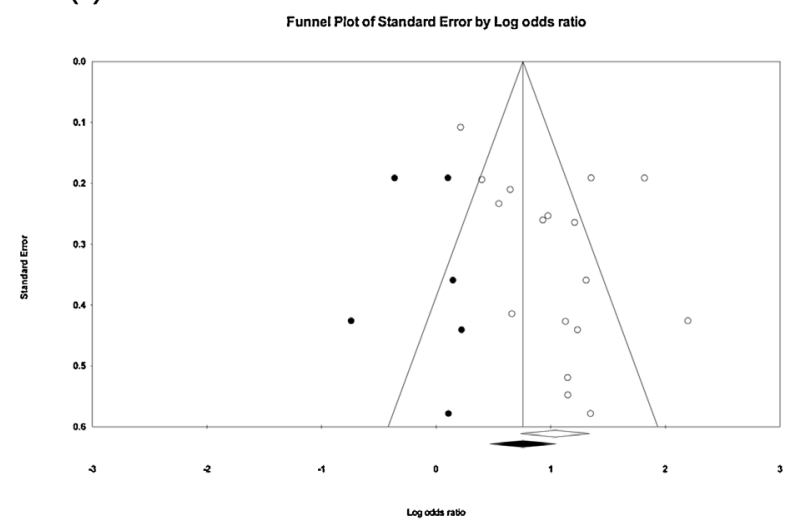

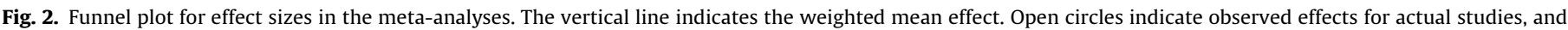

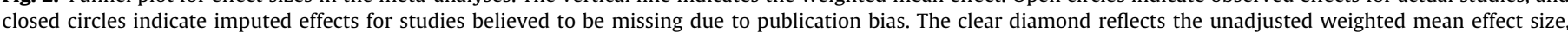
whereas the black diamond reflects the weighted mean effect size after adjusting for publication bias.

$2 a$. Overall emotion regulation and non-suicidal self-injury.

2b. Difficulties in Emotion Regulation - Lack of Emotional Awareness scale and non-suicidal self-injury.

2c. Difficulties in Emotion Regulation - Lack of Emotional Clarity scale and non-suicidal self-injury.

2d. Difficulties in Emotion Regulation - Difficulties Engaging in Goal-Directed Behavior scale and non-suicidal self-injury.

2e. Difficulties in Emotion Regulation - Impulse Control Difficulties scale and non-suicidal self-injury.

2f. Difficulties in Emotion Regulation - Non-acceptance of Emotional Responses scale and non-suicidal self-injury.

2g. Difficulties in Emotion Regulation - Limited Access to Emotion Regulation Strategies scale and non-suicidal self-injury.

2h. Emotion Regulation Questionnaire - Cognitive Reappraisal scale and non-suicidal self-injury.

2i. Emotion Regulation Questionnaire - Expressive Suppression scale and non-suicidal self-injury. 
(g)

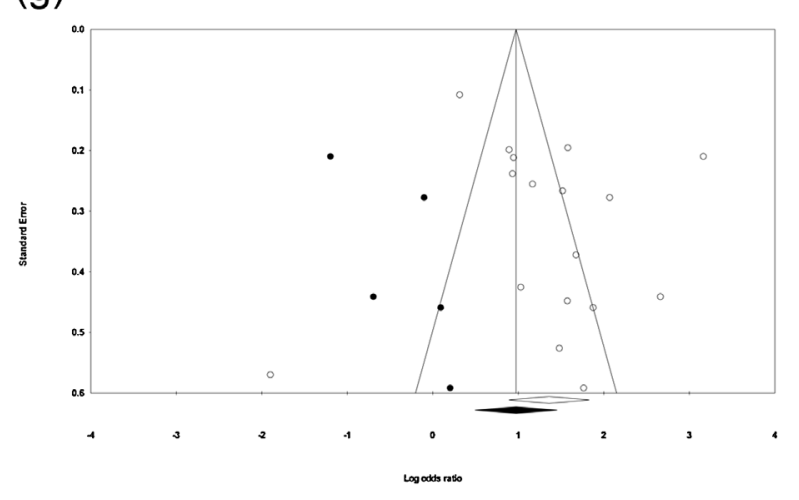

(i)

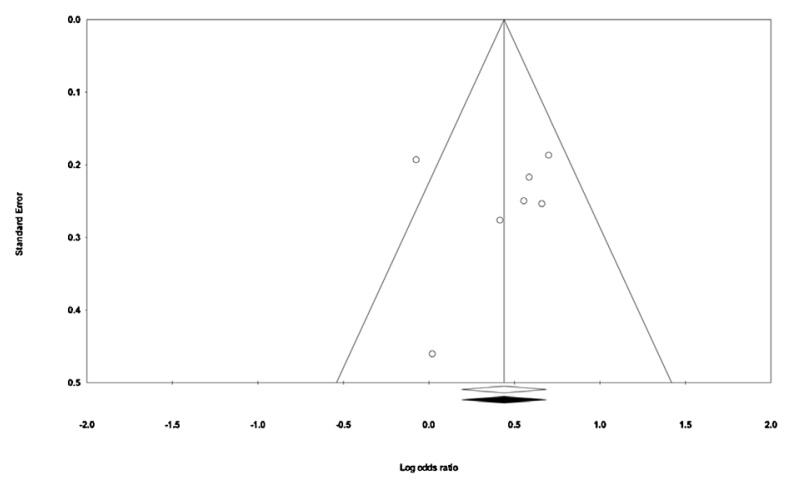

(h)

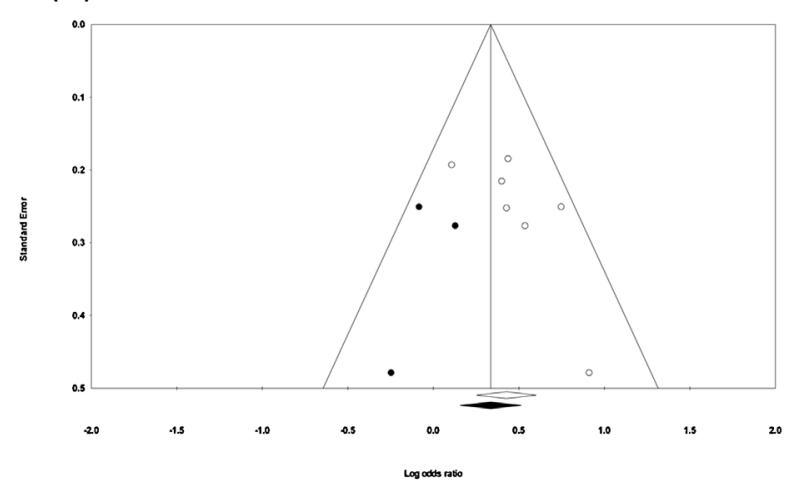

Fig. 2. (Continued)

\subsection{Data extraction}

To identify potential moderators, we extracted data on nine study characteristics. We included four sample characteristics: (i) sample age group (i.e., youth up to age 18 ) versus adult (including college age samples)); (ii) mean age of sample; (iii) sample clinical status (i.e., clinical/at-risk versus community); and (iv) percentage of female participants in the study sample. Data were also extracted for five study design characteristics: (i) form(s) of emotion dysregulation assessed; (ii) method of assessing emotion dysregulation (i.e., self-report versus task) ${ }^{2}$; (iii) method of assessing NSSI; (iv) time-frame of NSSI assessment (12 months or fewer versus lifetime); and (v) cross-sectional versus longitudinal analysis. Extraction was conducted by one of the investigators and $20.83 \%$ of studies were checked for accuracy.

\subsection{Data analysis}

Based on the inclusion criteria noted above, the included studies utilized one of three emotion dysregulation measures: the DERS, ERQ or CERQ. The DERS is a 36-item measure with 6 scales [11]: nonacceptance of emotional responses (i.e., "When I'm upset, I become angry with myself for feeling that way"), difficulty engaging in goal-directed behavior (i.e., "When I'm upset, I have difficulty getting work done"), impulse control difficulties (i.e., "I experience my emotions as overwhelming and out of control"), limited access to

\footnotetext{
${ }^{2}$ Although examining differences based on method of assessment of emotion dysregulation was intended, note that no studies meeting our criteria were identified that used task-based measures.
}

emotion regulation strategies (i.e., "When I'm upset, I believe there is nothing I can do to make myself feel better"), and lack of emotional clarity (i.e., "I am confused about how I feel"). The CERQ is a 36-item measure that assesses 9 scales of cognitive emotion regulation [27]. Of the 9 scales, only studies utilizing two of the scales, rumination/ focus on thought (i.e., "I am preoccupied with what I think and feel about what I have experience") and catastrophizing (i.e., "Thinking that what I experienced is the worst ever"), had enough studies to be included in the meta-analysis. Lastly, the ERQ is a 10 -item measure assessing cognitive reappraisal (i.e., "I change the way I'm thinking about the situation") and emotional suppression (i.e., "I control my emotions by not expressing them") [25].

For the primary index of effect size we report the odds ratio (OR). If ORs were not reported in the original articles, we derived them from available data reported in the study (e.g., means and standard deviations, correlation) whenever it was possible to do so. We calculated all ORs such that values greater than 1.0 indicate a positive association between emotion dysregulation and NSSI. To convert data into ORs and conduct all analyses, we used Comprehensive Meta-Analysis Version 3.3.070 [35] (Biostat, 2014). We calculated the overall weighted effect size by pooling ORs across all relevant studies. For all analyses, we generated random-effects models in preference to fixed-effects models, in order to account for the high expected heterogeneity across studies resulting from differences in samples, measures, and design. We evaluated this heterogeneity across studies using the $I^{2}$ statistic, which represents the percentage of the variance in an effect estimate that is a product of heterogeneity across studies rather than sampling error (i.e., chance). $I^{2}$ values of around $25 \%$ indicate low heterogeneity, while $I^{2}$ values of $50 \%$ indicate moderate heterogeneity. An $I^{2}$ value of $75 \%$ is an indicator of substantial 
Table 2

Meta-analytic results for the Difficulties in Emotion Regulation Scale in relation to non-suicidal self-injury.

\begin{tabular}{|c|c|c|c|c|c|c|c|c|c|}
\hline & \multicolumn{4}{|c|}{ Effect Size Analyses } & \multicolumn{2}{|c|}{ Heterogeneity Analyses } & \multicolumn{3}{|c|}{ Publication Bias Analyses } \\
\hline & \multirow[t]{2}{*}{$k$} & \multirow[t]{2}{*}{ OR } & \multirow[t]{2}{*}{$95 \% \mathrm{CI}$} & \multirow[t]{2}{*}{$p$} & \multirow[t]{2}{*}{$\mathrm{I}^{2}$} & \multirow[t]{2}{*}{$p$} & \multirow{2}{*}{$\begin{array}{l}\text { Egger's } \\
\text { regression } \\
\text { test } p\end{array}$} & \multicolumn{2}{|c|}{ Trim-and-fill } \\
\hline & & & & & & & & OR & $95 \% \mathrm{CI}$ \\
\hline Overall emotion regulation & 41 & 3.03 & $2.56-3.59$ & $<.001$ & $82.61 \%$ & $<.001$ & $<.01$ & 2.40 & $2.01-2.86$ \\
\hline Lack of emotional awareness & 16 & 1.53 & $1.25-1.88$ & $<.001$ & $58.59 \%$ & $<.01$ & .53 & 1.56 & $1.27-1.91$ \\
\hline Lack of emotional clarity & 16 & 2.10 & $1.56-2.83$ & $<.001$ & $80.63 \%$ & $<.001$ & .15 & 2.10 & $1.56-2.83$ \\
\hline Difficulties engaging goal-directed behavior & 17 & 2.69 & $2.03-3.55$ & $<.001$ & $78.71 \%$ & $<.001$ & $<.01$ & 2.13 & $1.66-2.73$ \\
\hline Impulse control difficulties & 18 & 2.70 & $2.05-3.56$ & $<.001$ & $79.40 \%$ & $<.001$ & $<.05$ & 2.70 & $2.05-3.56$ \\
\hline Non-acceptance of emotional responses & 17 & 2.82 & $2.09-3.82$ & $<.001$ & $82.37 \%$ & $<.001$ & $<.05$ & 2.13 & $1.60-2.85$ \\
\hline Limited access to emotion regulation strategies & 17 & 3.89 & $2.44-6.23$ & $<.001$ & $92.70 \%$ & $<.001$ & .18 & 2.65 & $1.64-4.28$ \\
\hline
\end{tabular}

Note: $k=$ number of unique effects; $\mathrm{OR}=$ pooled odds ratio; $\mathrm{CI}=$ confidence interval.

heterogeneity that is due to real differences in study samples and methodology, which suggests that the observed heterogeneity is over and above what would be expected with random error (Higgins, Thompson, Deeks, \& Altman, 2003). When high heterogeneity is observed, random-effects models are preferred over fixed-effects models-random-effects models account for this heterogeneity by incorporating both sampling and study-level errors, with the pooled effect size representing the mean of a distribution of true effect sizes instead of a single true effect size. Conversely, fixed-effects models estimate only within-study variance because they assume that a single true effect size exists across all studies and any variance detected is due strictly to sampling error.

Findings with high heterogeneity suggest it is necessary to conduct moderator analyses to uncover potential sources of this heterogeneity. Potential moderators were evaluated using random effects analysis. We first assessed each potential moderator separately, and calculated an estimate of the effect size at each level of the moderator. Moderators that reached the threshold of $p>0.05$ are reported.

When interpreting the results of meta-analyses, a common concern is the possible influence of publication bias. That is, because studies with small effect sizes or non-significant findings are less likely to be published, their findings may be left out of meta-analyses. This can potentially lead to inflation of estimates of the overall effect size. We evaluated potential publication bias by calculating the following publication bias indices: Duval and Tweedie's trim-and-fill analysis (Duval \& Tweedie, 2000) and Egger's regression intercept(Egger, Davey Smith, Schneider, \& Minder, 1997). Duval and Tweedie's trim-and-fill analysis generates an estimate of the number of missing studies based on asymmetry in a funnel plot of the standard error of each study in a meta-analysis (based on the study's sample size) compared to the study's effect size. This analysis also yields an effect size estimate and confidence interval, adjusting for these missing studies. We note that this procedure assumes effect sizes to be homogeneous; therefore, if significant heterogeneity exists, results should be interpreted with caution. Egger's regression intercept derives potential publication bias indices by using a linear regression approach that assesses study effect sizes compared to their standard error.

\section{Results}

The present meta-analysis included 48 publications based on 49 unique samples ${ }^{3}$ assessing the relation between emotion dysregulation and NSSI (see Table 1). We first present results for

\footnotetext{
${ }^{3}$ Three publications reported on multiple samples. As noted above, an additional three samples were reported in six publications.
}

overall emotion dysregulation and moderator analyses for overall emotion dysregulation, followed by analyses for the association between NSSI and specific dimensions of emotion dysregulation as reflected by the DERS, ERQ, and CERQ, respectively.

\subsection{Overall emotion dysregulation and NSSI}

A total of 41 unique effects were identified for overall emotion dysregulation in relation to NSSI, with a positive weighted effect size observed (pooled $\mathrm{OR}=3.03$ [95\% CI = 2.56-3.59]). Heterogeneity was high, indicating that moderator analyses were appropriate. In terms of potential publication bias, Egger's regression test indicated that significant publication bias was present (intercept $=$ 1.89 [95\% CI $=.54-3.24$ ] $, t=2.82, p<.01$ ). Additionally, the funnel plot of effect sizes was notably asymmetrical (see Fig. 2a). When the trim-and-fill method was used to correct parameter estimates for potential publication bias, the adjusted weighted OR was reduced to $2.40(95 \% \mathrm{CI}=2.01-2.86)$ suggesting that there is a significant relation between emotion dysregulation and NSSI.

\subsection{Moderator analyses}

Most studies featured adult samples or a combination of adults and adolescents, with 10 studies featuring 8 purely adolescent samples. The majority of studies had samples that were predominantly female, with only 7 studies including mostly male samples. It should be noted that none of the identified studies included task data and all studies included in this review relied on self-report measures of emotion regulation. Consequently, this study design feature was not included in moderator analyses. Additionally, too few studies featured interview-based measures of NSSI or longitudinal analyses of emotion dysregulation in relation to NSSI for consideration in moderator analyses (i.e., < 3). Therefore, age, sex, sample type, and timing of NSSI were tested as moderators.

Age was not a significant moderator of the strength of the association between overall emotion dysregulation and NSSI, regardless of whether age was treated categorically with comparisons made between youth and adults $(p=.09)$ or analyzed as a continuous variable $(b=.02, p=.25)$. Similarly, we did not find the percentage of female participants in each study $(b<.01 . p=.33)$, or sample type (i.e., clinical/at-risk versus community; $p=.16$ ) were significant moderators. However, time frame of NSSI assessment emerged as a significant moderator $(p=.04)$, with a larger effect size in the relation between overall emotion dysregulation and NSSI observed for lifetime NSSI ( OR $=3.21[95 \% \mathrm{CI}=2.63-3.91])$ than for past-year NSSI (OR = $2.32[95 \% \mathrm{CI}=1.84-2.92]$ ).

We also conducted an analysis directly comparing individuals with recent NSSI (defined as engaging in this behavior in the past 12 months) with individuals with a past history of NSSI (defined as having engaged in this behavior, but not in the past 12 months), to 
ascertain whether recency of NSSI was associated with emotion dysregulation. Across the four studies that allowed for this analysis, a small-to-medium effect was observed, with recent NSSI associated with greater emotion dysregulation, relative to past NSSI $(\mathrm{OR}=1.68[95 \% \mathrm{CI}=1.03-2.73])$.

\subsection{DERS subscales}

Specific dimensions of emotion dysregulation as reflected by the DERS subscales were also examined in relation to NSSI (see Table 2). All domains of emotion dysregulation were positively associated with NSSI, with pooled OR's ranging from 1.53 (95\% $\mathrm{CI}=1.25-1.88$ ) for the lack of emotional awareness subscale to 3.89 (85\% $\mathrm{CI}=2.44-6.23$ ) for the limited access to emotion regulation strategies subscale. Regarding potential publication bias for specific DERS subscales, Egger's regression test indicated significant publication bias in the case of the non-acceptance of emotional responses scale, the difficulties engaging in goaldirected behavior scale, and impulse control difficulties scale. Funnel plots of the effect sizes for DERS subscales (see Figs. $2 \mathrm{~b}$ to $2 \mathrm{~g}$ ) were fairly asymmetrical in the case of the non-acceptance of emotional responses scale and the difficulties engaging in goaldirected behavior scale, suggesting the presence of publication bias, but not in the case of the impulse control difficulties scale. Additionally, the funnel plot for the limited access to emotion regulation strategies scale appeared asymmetrical. Although the trim-and-fill method produced a reduction in estimated effect sizes, significant effects remained for all DERS subscales, with adjusted OR's ranging from $1.56(95 \% \mathrm{CI}=1.27-1.91)$ for the lack of emotional awareness scale to $2.70(95 \% \mathrm{CI}=2.05-3.56)$ for the impulse control difficulties scale. These results are summarized in Table 1.

\subsection{ERQ subscales}

Seven studies were available for the ERQ subscales in relation to NSSI. Cognitive reappraisal difficulties (pooled OR $=1.53[95 \%$ $\mathrm{CI}=1.29-1.83]$ ) and expressive suppression (pooled $\mathrm{OR}=1.55[95 \%$ $\mathrm{CI}=1.21-1.99]$ ) were both positively associated with NSSI. There was no evidence of publication bias based on Egger's regression test for either ERQ subscale (for cognitive reappraisal difficulties, intercept $=2.44[95 \% \mathrm{CI}=-.71-5.59], t=1.99, p=.10$; for expressive suppression, intercept $=-.54[95 \% \mathrm{CI}=-6.72-5.64, t=.22, p=.83$ ). Asymmetry was present in the funnel plot for cognitive reappraisal difficulties but not for expressive suppression (Figs. $2 \mathrm{~h}$ and $2 \mathrm{i}$ ). Similarly, the effect size was reduced but remained significant for cognitive reappraisal difficulties (adjusted OR $=1.40[95 \% \mathrm{CI}=1.17$ 1.67]) but remained unchanged for expressive suppression.

\subsection{CERQ subscales}

A sufficient number of unique effects to calculate pooled effect sizes was available only for the subscales of the CERQ corresponding to the tendency to ruminate and to catastrophize as forms of emotion dysregulation $(k s=3)$. Small-to-medium pooled effects were observed in both cases $\left(\mathrm{OR}_{\mathrm{CERQ} \text { Rumination }}=1.83\right.$ $[95 \% \mathrm{CI}=1.30-2.58], \quad p=.001 ; \quad \mathrm{OR}_{\mathrm{CERQ}}$ Catastrophize $=1.79 \quad[95 \%$ $\mathrm{CI}=1.34-2.40], p<.001)$.

\section{Discussion}

Although emotion dysregulation is often cited as a primary reason that individuals engage in NSSI, previous reviews have not synthesized this literature. The current meta-analytic review aimed to characterize overall associations between emotion dysregulation and NSSI, and to examine patterns of association between NSSI and specific dimensions of emotion dysregulation. A total of 48 studies were identified, demonstrating the substantial attention devoted to this topic over the past several years. Consistent with prevailing theories of NSSI, results demonstrated a significant association between these constructs in the predicted direction, such that greater emotion dysregulation was associated with a greater likelihood to engage in NSSI. The overall pooled odds ratio was 2.40 , a medium effect size, with the strength of associations varying according to the dimension of emotion dysregulation analyzed. Results of the current meta-analysis have critical implications for the treatment and prevention of NSSI in both adolescents and adults.

Findings revealed a robust association between NSSI and emotion dysregulation across numerous samples, with no differences emerging based on sample age, sex, or sample type (i.e., clinical versus community). In prior meta-analyses of both coping and emotion regulation, age has been an inconsistent moderator of effects $[17,18]$, and in a recent meta-analysis examining associations among emotion regulation and anxiety and depressive symptoms, age was not a moderator of any effects [83]. This may be due in part to problems in measurement approaches that do not account for developmental differences and evaluation of emotion (dys)regulation across various ages [18]. Further, a small number of studies in the current meta-analysis reported effects for adolescents (as opposed to adults or combined), which may have limited our power to detect a significant moderating effect of age. Of all moderators assessed, only time frame of NSSI assessment emerged as significant, with a larger effect size observed for lifetime NSSI than for past-year NSSI. This finding may not be surprising given that measures of lifetime NSSI encompass a larger time frame, but is reflective of important measurement differences across studies of NSSI that may significantly impact results.

Across measures, some dimensions of emotion dysregulation were more strongly related to NSSI than others. The DERS subscale of limited access to emotion regulation strategies showed the greatest association with NSSI, with an effect size in the mediumto-large range. This finding is consistent with other studies that suggest the availability of multiple regulation strategies is a particularly important facet to consider in the assessment and treatment of NSSI and related symptoms [15,34]. Cognitive aspects of emotion dysregulation (i.e., poor reappraisal, catastrophizing, rumination, and suppression) showed weaker associations with NSSI, with odds ratios in the small-to-medium range. Such findings suggest that treatment efforts may benefit from a focus on helping patients to learn and access specific emotion regulation strategies considered more adaptive, such as reappraisal, distraction, or mindfulness, in preventing NSSI. However, it should be noted that considerably more studies included the measurement of emotion dyregulation using the DERS compared to the CERQ (which includes rumination and catastrophizing), pointing to the need for further research to examine these strategies in greater depth.

Our findings complement those of a previous meta-analysis examining risk factors for NSSI [33]. Although we did not examine specific diagnoses in this review, findings are consistent with prior analyses of the link between emotion regulation strategies and psychopathology, including depression, anxiety, eating disorders, and substance use [17], as well as broader internalizing and externalizing problems [18]. Compared to Fox and colleagues [33], our findings suggest a stronger association between emotion dysregulation and NSSI, which may reflect our inclusion of both cross-sectional and longitudinal studies, and/or our narrower definition of emotion dysregulation. In particular, the current meta-analysis excludes measures of emotional reactivity. Prior work suggests that emotion dysregulation may uniquely predict NSSI over and above emotional reactivity, while the reverse may not be true [82]. This suggests that emotion dysregulation may 
serve as a unique correlate of NSSI, as well as a particularly fruitful treatment target. In addition, given the complexity of the construct of emotion dysregulation and guided by the extended process model, research that examines each component of the emotion regulation process, from identification to implementation, is needed. While the current review demonstrates overall associations between NSSI and emotion dysregulation, further research is needed to better understand how and at what point the emotion regulation process contributes to greater likelihood of engaging in self-harm.

Meta-analyses by Aldao et al. and Compas et al. reveal significant associations between emotion (dys)regulation and psychopathology [17,18]. These meta-analyses find significant associations between psychopathology and cognitive reappraisal and secondary control coping (which includes cognitive reappraisal). Our findings expand on these meta-analyses, suggesting a small association between cognitive reappraisal and NSSI. However, it is interesting to note that although the current results reveal a medium-to-large effect size for the association between non-acceptance of emotional responses and NSSI, Aldao and colleagues found no association between non-acceptance and psychopathology. As they pointed out, these two strategies (reappraisal and acceptance of emotional response) are often important components of treatments that address emotion dysregulation, such as cognitive behavioral therapy and dialectical behavior therapy. This suggests that facilitating acceptance of emotional responses may be an advantageous treatment target that is specific to decreasing NSSI behavior. It is possible that our finding of a stronger relation between non-acceptance and NSSI differs from Aldao et al. because NSSI is a transdiagnostic behavior and is not specific to one diagnostic category [17]. NSSI may be a coping behavior (serving to distract or avoid) that results from non-acceptance of emotional responses [84,85]; however, more research is needed to further clarify these discrepant findings.

Our results demonstrate evidence of links between wellcharacterized emotion regulation strategies that protect against and increase risk for psychopathology, and NSSI. Although NSSI represents a transdiagnostic type of psychopathology manifested in behavior, it shares features of other types of psychopathology, and may benefit from similar interventions. At the same time, NSSI may pose unique challenges, in that the function of this behavior may actually be to regulate emotion. This requires successful treatments to not only facilitate the use of adaptive emotion regulation strategies, but also to provide alternate behaviors in which to engage under circumstances of heightened emotion or reactivity. Aldao et al. (2010) suggest that the strategies of rumination, avoidance, and suppression are risk factors for psychopathology, whereas reappraisal, problem-solving, and acceptance may serve as protective factors [17]. Our results similarly show that NSSI is positively associated with rumination and suppression (risk factors), as well as with reappraisal difficulties and non-acceptance (inverted protective factors). Avoidance and problem-solving were not included as subscales in the current meta-analysis. However, it is possible that the strategy we found with the strongest association to NSSI-lack of access to emotion regulation strategies-may represent one facet of a broader problem-solving construct. That is, part of problemsolving is generating possible solutions and without the ability to identify other emotion regulation strategies, an individual may rely on NSSI to cope with stressors or intense emotions. Indeed, prior work highlights that NSSI may serve as both a response to negative affect and a strategy for regulating it [30].

It should also be noted that while the current meta-analysis helps to advance our understanding of the relationship between emotion dysregulation and NSSI, the reasons for this association remain unknown. Some theories have posited that NSSI serves as a means of regulating emotions by avoiding or distracting from emotional experiences [29,32]. Others have suggested that because of the high degree of overlap between physical and emotional pain, the physical pain relief associated with NSSI leads to emotional pain relief [47]. Our findings, however, reflect associations between overall (i.e., trait-level) emotion dysregulation and NSSI, and cannot disentangle state-specific experiences of dysregulation that may prompt episodes of NSSI. These potential mechanisms of affect regulation in individuals engaging in NSSI, and the specific time frames in which they occur, are important to identify as they may provide future targets for treatment interventions. Understanding these mechanisms is an important step toward developing more effective treatments for NSSI.

\subsection{Limitations and future directions}

The current meta-analysis reveals a number of limitations with the current literature and highlights important future directions. First, the included studies relied exclusively on self-report measures of emotion dysregulation and NSSI, which is inherently limited in its ability to provide objective and corroborated data [86]. Although the current study initially aimed to include psychophysiological studies, there was an insufficient number identified in the current review of the literature that met our inclusion criteria for conducting a meta-analysis. Researchers have begun to rely on objective, psychophysiological measures believed to index emotion regulatory capacity-such as respiratory sinus arrhythmia $[87,88]$ and cardiac vagal tone measured through heart rate variability [89]. The reliance on self-report of emotion dysregulation limits findings, especially because experimental and psychophysiological studies have often failed to show the same results as self-report studies [90-92]. While incorporating constructs related to emotion dysregulation (e.g., reactivity) was outside the scope of the current meta-analytic review, exploring the role of emotional reactivity and regulatory capacity, as measured by psychophysiological measures, is an important continued area of future research in understanding mechanisms involved in NSSI behaviors. To date, studies have demonstrated associations between parasympathetic responses, including RSA, as a proxy for emotion regulation and psychopathology, including NSSI [93-95]. In addition, the regulation of emotion relies on a broad range of neurobiological mechanisms that assist in the identification of emotion, selection and implementation of emotion regulation strategies, which have been studied widely in adolescents and adults $[20,96,97]$. The integration of self-report, neurobiological, and psychophysiological measurement in understanding regulatory processes and their association with NSSI across development is a critical area of future research.

Furthermore, many studies failed to assess the intention of self-harm and were therefore excluded from analyses due to their inability to discern if these were suicidal or non-suicidal acts. Imprecision of measurement and/or language may yield inconsistent results and produce conflictual conclusions in the literature, motivating our decision to exclude many studies at the risk of omitting potentially meaningful data. Although various questionnaires were used to assess NSSI and continuous data was used whenever possible, nearly half of the studies reviewed relied on binary coding (e.g., yes/no NSSI) and did not account for factors such as frequency and severity of NSSI. The use of more nuanced measures of NSSI may yield more detailed information about this construct and its relationship to emotion dysregulation. In addition, it is possible that distinct subdomains of NSSI show differential associations with emotion dysregulation. Future research should empirically examine the strength of associations between subdomains of both NSSI and emotion dysregulation. 
Most of the included studies relied on cross-sectional assessment of variables. While these data offer an interesting "snap shot" of emotion dysregulation and NSSI, longitudinal studies of these phenomena will offer insight into the persistence, and coevolution of these processes overtime. Furthermore, longitudinal methodology is necessary to determine true risk factors for NSSI and elucidate the causal relationship between variables of interest [98]. Additionally, prospective studies, especially those including ecological momentary assessment methodology, could offer more accurate periodic or "real-time" reports of behavior, rather than relying on retrospective reports of emotionally laden experiences which may be influenced by recall biases $[99,100]$. Finally, future studies should aim to include a diverse range of subjects across demographic factors such as race/ethnicity, sex and gender, age, and psychiatric diagnoses. Although the current findings revealed no difference in associations between emotion dysregulation and NSSI based on age or sex, the majority of samples were primarily or exclusively female, limiting any definitive conclusions. In addition, sample type (clinical versus community) did not affect associations between emotion dysregulation and NSSI; however, specific diagnostic features (i.e., symptoms, diagnoses) should be considered in future work.

\section{Conclusion}

The current meta-analysis synthesizes over a decade of empirical research examining associations between emotion dysregulation and NSSI. Findings provide support for the notion that greater emotion dysregulation is associated with higher likelihood of engagement in NSSI among individuals across settings, regardless of age or sex. Furthermore, findings reveal facets of emotion dysregulation, such as limited access to emotion regulation strategies, may have unique implications for NSSI risk. NSSI is highly prevalent within clinical samples and represents a critical risk factor for suicide attempts. This meta-analysis highlights the importance of better understanding emotion dysregulation as a treatment target for preventing NSSI.

\section{Contributors}

All authors made substantial contributions to this work. All authors participated in the conception and refinement of the manuscript objectives, literature review, and manuscript writing and editing. Dr. Liu conducted the systematic literature search and all statistical analyses.

\section{Funding}

This research did not receive any specific grant from funding agencies in the public, commercial, or not-for-profit sectors.

\section{Conflict of interest statement}

The authors have no real or potential conflicts of interest to declare.

\section{Acknowledgements}

The authors would like to thank all individuals who replied to inquires regarding previously published findings. The authors are grateful for support from the National Institute of Mental Health (T32MH019927; T32MH078788) and American Foundation for Suicide Prevention (PDF-010517). The content is solely the responsibility of the authors and does not necessarily reflect the official views of the National Institutes of Health or AFSP.

\section{References}

[1] Nock MK. Self-injury. Annu Rev Clin Psychol 2010;6:339-63, doi:http://dx doi.org/10.1146/annurev.clinpsy.121208.131258.

[2] Swannell SV, Martin GE, Page A, Hasking P, St John NJ. Prevalence of nonsuicidal self-injury in nonclinical samples: systematic review, metaanalysis and meta-regression. Suicide Life-Threatening Behav 2014;44:273303, doi:http://dx.doi.org/10.1111/sltb.12070.

[3] Briere J, Gil E. Self-mutilation in clinical and general population samples: prevalence, correlates, and functions. Am J Orthopsychiatry 1998:68:609-20.

[4] Cloutier P, Martin J, Kennedy A, Nixon MK, Muehlenkamp JJ. Characteristics and co-occurrence of adolescent non-suicidal self-injury and suicidal behaviours in pediatric emergency crisis services. J Youth Adolesc 2010;39:259-69, doi:http://dx.doi.org/10.1007/s10964-009-9465-1.

[5] Darche M. Psychological factors differentiating self-mutilating and non-selfmutilating adolescent inpatient females. Psychiatr Hosp 1990;21:31-5.

[6] Hawton K, Saunders KEA, O'Connor RC. Self-harm and suicide in adolescents. Lancet 2012;379:2373-82, doi:http://dx.doi.org/10.1016/S0140-6736(12) 60322-5.

[7] Hamza CA, Stewart SL, Willoughby T. Examining the link between nonsuicidal self-injury and suicidal behavior: a review of the literature and an integrated model. Clin Psychol Rev 2012;32:482-95, doi:http://dx. doi.org/10.1016/j.cpr.2012.05.003.

[8] Asarnow JR, Porta G, Spirito A, Emslie G, Clarke G, Wagner KD, et al. Suicide attempts and nonsuicidal self-injury in the treatment of resistant depression in adolescents: findings from the TORDIA study. J Am Acad Child Adolesc Psychiatry 2011:50:772-81.

[9] Ribeiro JD, Franklin JC, Fox KR, Bentley KH, Kleiman EM, Chang BP, et al. Selfinjurious thoughts and behaviors as risk factors for future suicide ideation, attempts, and death: a meta-analysis of longitudinal studies. Psychol Med 2016:46:225-36, doi:http://dx.doi.org/10.1017/S0033291715001804.

[10] Wilkinson P, Kelvin R, Roberts C, Dubicka B, Goodyer I. Clinical and psychosocial predictors of suicide attempts and nonsuicidal self-injury in the Adolescent Depression Antidepressants and Psychotherapy Trial (ADAPT). Am J Psychiatry 2011;168:495-501, doi:http://dx.doi.org/10.1176/appi. ajp.2010.10050718

[11] Gratz KL, Roemer L. Multidimensional assessment of emotion regulation and dysregulation: development, factor structure, and initial validation of the difficulties in emotion regulation scale. J Psychopathol Behav Assess 2004;26:41-54, doi:http://dx.doi.org/10.1023/B: JOBA.0000007455.08539.94.

[12] Gross JJ. Emotion regulation: affective, cognitive, and social consequences. Psychophysiology 2002;39:281-91, doi:http://dx.doi.org/10.1017/ S0048577201393198.

[13] Mennin DS, Holaway RM, Fresco DM, Moore MT, Heimberg RG. Delineating components of emotion and its dysregulation in anxiety and mood psychopathology. Behav Ther 2007;38:284-302, doi:http://dx.doi.org/ 10.1016/j.beth.2006.09.001.

[14] Thompson RA. Emotion regulation: a theme in search of definition. Monogr Soc Res Child Dev 1994;59:25-52.

[15] Perez J, Venta A, Garnaat S, Sharp C. The difficulties in emotion regulation scale: factor structure and association with nonsuicidal self-injury in adolescent inpatients. J Psychopathol Behav Assess 2012;34:393-404, doi: http://dx.doi.org/10.1007/s10862-012-9292-7.

[16] Aldao A, Gee DG, De Los Reyes A, Seager I. Emotion regulation as transdiagnostic factor in the development of internalizing and externalizing psychopathology: current and future directions. Dev Psychopathol 2016;28:927-46, doi:http://dx.doi.org/10.1017/S0954579416000638.

[17] Aldao A, Nolen-Hoeksema S, Schweizer S. Emotion-regulation strategies across psychopathology: a meta-analytic review. Clin Psychol Rev 2010;30:217-37, doi:http://dx.doi.org/10.1016/j.cpr.2009.11.004.

[18] Compas BE, Jaser SS, Bettis AH, Watson KH, Gruhn MA, Dunbar JP, et al. Coping, emotion regulation, and psychopathology in childhood and adolescence: a meta-analysis and narrative review. Psychol Bull 2017;143 (9):939.

[19] Gross JJ. Emotion regulation: current status and future prospects. Psychol Inq 2015;26:1-26, doi:http://dx.doi.org/10.1080/1047840X.2014.940781.

[20] Ochsner KN, Ray RR, Hughes B, McRae K, Cooper JC, Weber J, et al. Bottom-up and top-down processes in emotion generation: common and distinct neural mechanisms. Psychol Sci 2009;20(11):1322-31.

[21] Phillips ML, Ladouceur CD, Drevets WC. A neural model of voluntary and automatic emotion regulation: implications for understanding the pathophysiology and neurodevelopment of bipolar disorder. Mol Psychiatry 2008;13(9):833.

[22] Gross JJ. The emerging field of emotion regulation: an integrative review. Rev Gen Psychol 1998;2:271-99, doi:http://dx.doi.org/10.1037/10892680.2.3.271.

[23] Gross JJ, Sheppes G, Urry HL. Cognition and emotion lecture at the 2010 SPSP emotion preconference. Cogn Emot 2011;25:765-81, doi:http://dx.doi.org/ 10.1080/02699931.2011.555753.

[24] Gross JJ. Emotion regulation in adulthood: timing is everything. Curr Dir Psychol Sci 2001;10:214-9, doi:http://dx.doi.org/10.1111/1467-8721.00152.

[25] Gross JJ, John OP. Individual differences in two emotion regulation processes: implications for affect, relationships, and well-being. J Pers Soc Psychol 2003;85:348-62, doi:http://dx.doi.org/10.1037/0022-3514.85.2.348. 
[26] Garnefski N, Kraaij V, Spinhoven P. Negative life events, cognitive emotion regulation and emotional problems. Pers Individ Dif 2001;30:1311-27, doi: http://dx.doi.org/10.1016/S0191-8869(00)00113-6.

[27] Garnefski N, Kraaij V. The cognitive emotion regulation questionnaire. Eur ] Psychol Assess 2007;23:141-9, doi:http://dx.doi.org/10.1027/10155759.23.3.141.

[28] Brown MZ, Comtois KA, Linehan MM. Reasons for suicide attempts and nonsuicidal self-injury in women with borderline personality disorder. J Abnorm Psychol 2002;111:198-202.

[29] Chapman AL, Gratz KL, Brown MZ. Solving the puzzle of deliberate self-harm: the experiential avoidance model. Behav Res Ther 2006;44:371-94.

[30] Klonsky ED. The functions of deliberate self-injury: a review of the evidence. Clin Psychol Rev 2007;27:226-39, doi:http://dx.doi.org/10.1016/j. cpr.2006.08.002.

[31] Linehan M. Cognitive behavioral treatment of borderline personality disorder. Guilford Press; 1993.

[32] Selby EA, Joiner TE. Cascades of emotion: the emergence of borderline personality disorder from emotional and behavioral dysregulation. Rev Gen Psychol 2009;13:219-29, doi:http://dx.doi.org/10.1037/a0015687.

[33] Fox KR, Franklin JC, Ribeiro JD, Kleiman EM, Bentley KH, Nock MK. Metaanalysis of risk factors for nonsuicidal self-injury. Clin Psychol Rev 2015;42:156-67, doi:http://dx.doi.org/10.1016/j.cpr.2015.09.002.

[34] Wolff JC, Davis S, Liu RT, Cha CB, Cheek SM, Nestor BA, et al. Trajectories of suicidal ideation among adolescents following psychiatric hospitalization. Abnorm Child Psychol 2018;46:355-63, doi:http://dx.doi.org/10.1007/ s10802-017-0293-6.

[35] Borenstein M, Hedges L, Higgins J, Rothstein H. Comprehensive MetaAnalysis Version 3. Englewood, NJ: Biostat; 2013.

[36] Anderson NL, Crowther JH. Using the experiential avoidance model of non suicidal self-injury: understanding who stops and who continues. Arch Suicide Res 2012;16:124-34, doi:http://dx.doi.org/10.1080/ 13811118.2012.667329.

[37] Anestis MD, Kleiman EM, Lavender JM, Tull MT, Gratz KL. The pursuit of death versus escape from negative affect: an examination of the nature of the relationship between emotion dysregulation and both suicidal behavior and non-suicidal self-injury. Compr Psychiatry 2014;55:1820-30, doi:http://dx. doi.org/10.1016/j.comppsych.2014.07.007.

[38] Arbuthnott AE, Lewis SP, Bailey HN. Rumination and emotions in nonsuicidal self-injury and eating disorder behaviors: a preliminary test of the emotiona cascade model. J Clin Psychol 2015;71:62-71, doi:http://dx.doi.org/10.1002/ jclp.22115.

[39] Bjureberg J, Ljótsson B, Tull MT, Hedman E, Sahlin H, Lundh L-G, et al. Development and validation of a brief version of the difficulties in emotion regulation scale: the DERS-16. J Psychopathol Behav Assess 2016;38:284-96, doi:http://dx.doi.org/10.1007/s10862-015-9514-x.

[40] Bracken-Minor KL, McDevitt-Murphy ME. Differences in features of nonsuicidal self-injury according to borderline personality disorder screening status. Arch Suicide Res 2014;18:88-103, doi:http://dx.doi.org/10.1080/ 13811118.2013.809040.

[41] Buckholdt KE, Parra GR, Anestis MD, Lavender JM, Jobe-Shields LE, Tull MT, et al. Emotion regulation difficulties and maladaptive behaviors: examination of deliberate self-harm, disordered eating, and substance misuse in two samples. Cognit Ther Res 2015;39:140-52, doi:http://dx.doi. org/10.1007/s10608-014-9655-3.

[42] Burke TA, Stange JP, Hamilton JL, Cohen JN, O’Garro-Moore J, Daryanani I, et al. Cognitive and emotion-regulatory mediators of the relationship between behavioral approach system sensitivity and nonsuicidal self-injury frequency. Suicide Life-Threatening Behav 2015;45:495-504, doi:http://dx. doi.org/10.1111/sltb.12145.

[43] Cerutti R, Presaghi F, Manca M, Gratz KL. Deliberate self-harm behavior among Italian young adults: correlations with clinical and nonclinical dimensions of personality. Am J Orthopsychiatry 2012;82:298-308, doi: http://dx.doi.org/10.1111/j.1939-0025.2012.01169.x.

[44] Chaplo SD, Kerig PK, Bennett DC, Modrowski CA. The roles of emotion dysregulation and dissociation in the association between sexual abuse and self-injury among juvenile justice-Involved youth. J Trauma Dissociation 2015:16:272-85, doi:http://dx.doi.org/10.1080/15299732.2015.989647.

[45] Duggan J, Heath N, Hu T. Non-suicidal self-injury maintenance and cessation among adolescents: a one-year longitudinal investigation of the role of objectified body consciousness, depression and emotion dysregulation. Child Adolesc Psychiatry Ment Health 2015;9:21, doi:http://dx.doi.org/10.1186/ s13034-015-0052-9.

[46] Emery AA, Heath NL, Mills DJ. Basic psychological need satisfaction, emotion dysregulation, and non-suicidal self-injury engagement in young adults: an application of self-determination theory. J Youth Adolesc 2016;45:612-23, doi:http://dx.doi.org/10.1007/s10964-015-0405-y.

[47] Franklin JC, Puzia ME, Lee KM, Lee GE, Hanna EK, Spring VL, et al. The nature of pain offset relief in nonsuicidal self-injury. Clin Psychol Sci 2013;1:110-9, doi:http://dx.doi.org/10.1177/2167702612474440.

[48] Gardner KJ, Dodsworth J, Selby EA. Borderline personality traits, rumination, and self-injurious behavior: an empirical test of the emotional cascades model in adult male offenders. J Forensic Psychol Pract 2014;14:398-417, doi: http://dx.doi.org/10.1080/15228932.2014.962379.

[49] Glenn CR, Klonsky ED. Nonsuicidal self-injury disorder: an empirical investigation in adolescent psychiatric patients. J Clin Child Adolesc
Psychol 2013:42:496-507, doi:http://dx.doi.org/10.1080/ 15374416.2013.794699.

[50] Gómez-Expósito A, Wolz I, Fagundo AB, Granero R, Steward T, JiménezMurcia S, et al. Correlates of non-suicidal self-injury and suicide attempts in bulimic Spectrum disorders. Front Psychol 2016;7:1244, doi:http://dx.doi. org/10.3389/fpsyg.2016.01244.

[51] Gratz KL, Chapman AL. The role of emotional responding and childhood maltreatment in the development and maintenance of deliberate self-harm among male undergraduates. Psychol Men Masc 2007;8:1-14, doi:http://dx. doi.org/10.1037/1524-9220.8.1.1.

[52] Gratz KL, Roemer L. The relationship between emotion dysregulation and deliberate self-harm among female undergraduate students at an urban commuter university. Cogn Behav Ther 2008;37:14-25, doi:http://dx.doi. org/10.1080/16506070701819524.

[53] Gratz KL, Tull MT. The relationship between emotion dysregulation and deliberate self-harm among inpatients with substance use disorders. Cognit Ther Res 2010;34:544-53, doi:http://dx.doi.org/10.1007/s10608-009-92684.

[54] Gratz KL, Breetz A, Tull MT. The moderating role of borderline personality in the relationships between deliberate self-harm and emotion-related factors. Personal Ment Health 2010;4(2):96-107.

[55] Muehlenkamp JJ, Bagge CL, Tull MT, Gratz KL. Body regard as a moderator of the relation between emotion dysregulation and nonsuicidal self-injury. Suicide Life-Threatening Behav 2013;43:, doi:http://dx.doi.org/10.1111/ sltb.12032 n/a-n/a.

[56] Hasking P, Momeni R, Swannell S, Chia S. The nature and extent of nonsuicidal self-injury in a non-clinical sample of young adults. Arch Suicide Res 2008;12:208-18, doi:http://dx.doi.org/10.1080/13811110802100957.

[57] Hasking PA, Coric SJ, Swannell S, Martin G, Thompson HK, Frost ADJ. Brief report: emotion regulation and coping as moderators in the relationship between personality and self-injury. J Adolesc 2010;33:767-73, doi:http:// dx.doi.org/10.1016/j.adolescence.2009.12.006.

[58] Heath N, Toste J, Nedecheva T, Charlebois A. An examination of nonsuicidal self-injury among college students. J Ment Health Couns 2008;30:137-56, doi:http://dx.doi.org/10.17744/mehc.30.2.8p879p3443514678.

[59] Horgan M, Martin G. Differences between current and past self-injurers: how and why do people stop? Arch. Arch Suicide Res 2016;20:142-52, doi:http:// dx.doi.org/10.1080/13811118.2015.1004479.

[60] Kleiman EM, Ammerman BA, Kulper DA, Uyeji LL, Jenkins AL, McCloskey MS. Forms of non-suicidal self-injury as a function of trait aggression. Compr Psychiatry 2015;59:21-7, doi:http://dx.doi.org/10.1016/j. comppsych.2014.12.004.

[61] Kranzler A, Fehling KB, Anestis MD, Selby EA. Emotional dysregulation, internalizing symptoms, and self-injurious and suicidal behavior: structural equation modeling analysis. Death Stud 2016;40:358-66, doi:http://dx.doi. org/10.1080/07481187.2016.1145156.

[62] Lear MK, Pepper CM. Self-concept clarity and emotion dysregulation in nonsuicidal self-injury. J Pers Dis 2016;30:813-27, doi:http://dx.doi.org/ 10.1521/pedi_2015_29_232.

[63] Levesque C, Lafontaine M-F, Bureau J-F. The mediating effects of emotion regulation and dyadic coping on the relationship between romantic attachment and non-suicidal self-injury. J Youth Adolesc 2017;46:277-87, doi:http://dx.doi.org/10.1007/s10964-016-0547-6.

[64] Martin A, White H, Flanagan TJ, Yensel NH, Bloomberg TV. A multisite study of the association between emotion dysregulation and deliberate self-harm among substance use disorder inpatients. Addict Disord Their Treat 2011;10:191-8, doi:http://dx.doi.org/10.1097/ADT.0b013e318223fc9e.

[65] Muehlenkamp JJ, Brausch AM. Reconsidering criterion a for the diagnosis of non-suicidal self-injury disorder. J Psychopathol Behav Assess 2016;38:54758, doi:http://dx.doi.org/10.1007/s10862-016-9543-0.

[66] Muehlenkamp JJ, Kerr PL, Bradley AR, Larsen MA. Abuse subtypes and nonsuicidal self-injury: preliminary evidence of complex emotion regulation patterns. J Nerv Ment Dis 2010;198:258-63, doi:http://dx.doi.org/10.1097/ NMD.0b013e3181d612ab.

[67] Muehlenkamp JJ, Peat CM, Claes L, Smits D. Self-injury and disordered eating: expressing emotion dysregulation through the body. Suicide LifeThreatening Behav 2012;42:416-25, doi:http://dx.doi.org/10.1111/j.1943278X.2012.00100.x

[68] Navarro-Haro MV, Wessman I, Botella C, García-Palacios A. The role of emotion regulation strategies and dissociation in non-suicidal self-injury for women with borderline personality disorder and comorbid eating disorder. Compr Psychiatry 2015;63:123-30, doi:http://dx.doi.org/10.1016/j. comppsych.2015.09.001.

[69] Sharp C, Ha C, Michonski J, Venta A, Carbone C. Borderline personality disorder in adolescents: evidence in support of the Childhood Interview for DSM-IV Borderline Personality Disorder in a sample of adolescent inpatients. Compr Psychiatry 2012;53(6):765-74.

[70] Peters JR, Smart LM, Baer RA. Dysfunctional responses to emotion mediate the cross-sectional relationship between rejection sensitivity and borderline personality features. J Pers Disord 2015;29:231-40, doi:http://dx.doi.org/ 10.1521/pedi_2014_28_151.

[71] Preyde M, Vanderkooy J, Chevalier P, Heintzman J, Warne A, Barrick K. The psychosocial characteristics associated with NSSI and suicide attempt of youth admitted to an in-patient psychiatric unit. J Can Acad Child Adolesc Psychiatry 2014;23:100-10. 
[72] Selby EA, Anestis MD, Bender TW, Joiner TE. An exploration of the emotional cascade model in borderline personality disorder. J Abnorm Psychol 2009;118:375-87, doi:http://dx.doi.org/10.1037/a0015711.

[73] Somma A, Sharp C, Borroni S, Fossati A. Borderline personality disorder features, emotion dysregulation and non-suicidal self-injury: preliminary findings in a sample of community-dwelling Italian adolescents. Personal Ment Health 2017;11:23-32, doi:http://dx.doi.org/10.1002/pmh.1353.

[74] Tatnell R, Kelada L, Hasking P, Martin G. Longitudinal analysis of adolescent NSSI: the role of intrapersonal and interpersonal factors. J Abnorm Child Psychol 2014;42(6):885-96.

[75] Voon D, Hasking P, Martin G. The roles of emotion regulation and ruminative thoughts in non-suicidal self-injury. Br J Clin Psychol 2014;53:95-113, doi: http://dx.doi.org/10.1111/bjc.12030.

[76] Turner BJ, Yiu A, Layden BK, Claes L, Zaitsoff S, Chapman AL. Temporal associations between disordered eating and nonsuicidal self-injury: examining symptom overlap over 1 year. Behav Ther 2015;46:125-38, doi: http://dx.doi.org/10.1016/j.beth.2014.09.002.

[77] Vieira AI, Ramalho S, Brandão I, Saraiva J, Gonçalves S. Adversity, emotion regulation, and non-suicidal self-injury in eating disorders. Eat Disord 2016;24:440-52, doi:http://dx.doi.org/10.1080/10640266.2016.1198205.

[78] Weinberg A, Klonsky ED. The effects of self-injury on acute negative arousal: a laboratory simulation. Motiv Emot 2012;36:242-54, doi:http://dx.doi.org/ 10.1007/s11031-011-9233-x.

[79] Wilcox HC, Arria AM, Caldeira KM, Vincent KB, Pinchevsky GM, O’Grady KE. Longitudinal predictors of past-year non-suicidal self-injury and motives among college students. Psychol Med 2012;42:717-26, doi:http://dx.doi.org/ $10.1017 /$ S0033291711001814.

[80] Williams F, Hasking P. Emotion regulation, coping and alcohol use as moderators in the relationship between non-suicidal self-injury and psychological distress. Prev Sci 2010;11:33-41, doi:http://dx.doi.org/10.1007/ s11121-009-0147-8.

[81] Yurkowski K, Martin J, Levesque C, Bureau J-F, Lafontaine M-F, Cloutier P. Emotion dysregulation mediates the influence of relationship difficulties on non-suicidal self-injury behavior in young adults. Psychiatry Res 2015;228:871-8, doi:http://dx.doi.org/10.1016/j.psychres.2015.05.006.

[82] Zelkowitz RL, Cole DA, Han GT, Tomarken AJ. The incremental utility of emotion regulation but not emotion reactivity in nonsuicidal self-injury. Suicide Life-Threatening Behav 2016;46:545-62, doi:http://dx.doi.org/ $10.1111 /$ sltb.12236.

[83] Schäfer JÖ, Naumann E, Holmes EA, Tuschen-Caffier B, Samson AC. Emotion regulation strategies in depressive and anxiety symptoms in youth: a metaanalytic review. J Youth Adolesc 2017;46(2):261-76.

[84] García-Nieto R, Carballo JJ, Díaz de Neira Hernando M, de León-Martinez V, Baca-García E. Clinical correlates of non-suicidal self-injury (NSSI) in an outpatient sample of adolescents. Arch Suicide Res 2015;19:218-30, doi: http://dx.doi.org/10.1080/13811118.2014.957447.

[85] Lloyd-Richardson EE, Perrine N, Dierker L, Kelley ML. Characteristic and functions on non-suicidal self-injury in a community sample of adolescents. Psychol Med 2007;37:1183-92, doi:http://dx.doi.org/10.1017/ S003329170700027X

[86] Folkman S, Moskowitz JT. Coping: pitfalls and promise. Annu Rev Psychol 2004;55:745-74.
[87] Beauchaine TP. Respiratory sinus arrhythmia: a transdiagnostic biomarker of emotion dysregulation and psychopathology. Curr Opin Psychol 2015;3:437.

[88] Wielgus MD, Aldrich JT, Mezulis AH, Crowell SE. Respiratory sinus arrhythmia as a predictor of self-injurious thoughts and behaviors among adolescents. Int J Psychophysiol 2016;106:127-34, doi:http://dx.doi.org/10.1016/j. ijpsycho.2016.05.005.

[89] Laborde S, Mosley E, Thayer JF. Heart rate variability and cardiac vagal tone in psychophysiological research - recommendations for experiment planning, data analysis, and data reporting. Front Psychol 2017;8:213, doi:http://dx.doi org/10.3389/fpsyg.2017.00213.

[90] Franklin JC, Hessel ET, Aaron RV, Arthur MS, Heilbron N, Prinstein MJ. The functions of nonsuicidal self-injury: support for cognitive-affective regulation and opponent processes from a novel psychophysiological paradigm. J Abnorm Psychol 2010;119:850-62, doi:http://dx.doi.org/ 10.1037/a0020896.

[91] Glenn CR, Blumenthal TD, Klonsky ED, Hajcak G. Emotional reactivity in nonsuicidal self-injury: divergence between self-report and startle measures. Int J Psychophysiol 2011;80:166-70, doi:http://dx.doi.org/ 10.1016/j.ijpsycho.2011.02.016.

[92] Kaess M, Hille M, Parzer P, Maser-Gluth C, Resch F, Brunner R. Alterations in the neuroendocrinological stress response to acute psychosocial stress in adolescents engaging in nonsuicidal self-injury. Psychoneuroendocrinology 2012;37:157-61, doi:http://dx.doi.org/10.1016/j.psyneuen.2011.05.009.

[93] Crowell SE, Butner J, Wiltshire TJ, Munion AK, Yaptangco M, Beauchaine TP. Evaluating emotional and biological sensitivity to maternal behavior among depressed and self-injuring adolescent girls using nonlinear dynamics. Clin Psychol Sci 2017;5:272-85.

[94] Stange JP, Hamilton JL, Fresco DM, Alloy LB. Flexible parasympathetic responses to sadness facilitate spontaneous affect regulation. Psychophysiology 2017;54(7):1054-69.

[95] Yaroslavsky I, Rottenberg J, Bylsma LM, Jennings JR, George C, Baji I, et al. Parasympathetic nervous system activity predicts mood repair use and its effectiveness among adolescents with and without histories of major depression. J Abnorm Psychol 2016;125(3):323.

[96] Pagliaccio D, Luby JL, Luking KR, Belden AC, Barch DM. Brain-behavior relationships in the experience and regulation of negative emotion in healthy children: implications for risk for childhood depression. Dev Psychopathol 2014;26(4pt2):1289-303.

[97] Sheppes G, Scheibe S, Suri G, Radu P, Blechert J, Gross JJ. Emotion regulation choice: a conceptual framework and supporting evidence. J Exp Psychol Gen 2014;143(1):163.

[98] Kraemer HC, Kazdin AE, Offord DR, Kessler RC, Jensen PS, Kupfer DJ. Coming to terms with the terms of risk. Arch Gen Psychiatry 1997;54:337-43.

[99] Nock MK, Prinstein MJ, Sterba SK. Revealing the form and function of selfinjurious thoughts and behaviors: a real-time ecological assessment study among adolescents and young adults. J Abnorm Psychol 2009;118(4):816-27, doi:http://dx.doi.org/10.1037/a0016948.

[100] Solhan MB, Trull TJ, Jahng S, Wood PK. Clinical assessment of affective instability: comparing EMA indices, questionnaire reports, and retrospective recall. Psychol Assess 2009;21:425-36, doi:http://dx.doi.org/10.1037/ a0016869. 